\title{
Serum lipoproteins in multiple sclerosis determined by cellulose acetate electrophoresis ${ }^{1}$
}

\author{
K. GAVRilesCU, R. S. MELliCK ${ }^{2}$, AND W. H. McMENEMEY \\ Maida Vale Hospital for Nervous Diseases, London
}

In previous papers (Gavrilescu, Jellinek, and McMenemey, 1961, Gavrilescu and McMenemey, 1964) on comparative studies on the protein fractions in the serum and cerebrospinal fluid in multiple sclerosis we have noted increases in the $\alpha_{2}$ and $\beta$ globulins in the serum. Although not specific for this disease these changes are of interest, particularly as multiple sclerosis is considered to be purely a disease of the central nervous system unassociated with primary systemic disturbances or manifestations. As the greatest proportion of the lipoproteins on cellulose acetate migrate at a similar rate to the $\alpha_{2}$ globulins we thought it important to investigate the possibility of an increase in the lipoproteins influencing the protein pattern, and in particular, the globulin changes mentioned above.

\section{MATERIAL}

Our material consists of 43 cases of multiple sclerosis. Of these 28 had what was considered, on clinical grounds, to be active disease, while 15 had chronic disease without evidence of any change over the period of observation. Their ages varied between 18 and 68 years. The sex distribution was approximately equal. Our normal controls consisted of 27 healthy adults taken from a slightly younger age group (20-40) with an approximately equal sex distribution.

Serum was collected in the fasting state from the controls and from 19 of the multiple sclerosis cases. The other 24 sera were post-absorptive, blood having been taken from patients soon after a light breakfast or at different hours of the afternoon. Most specimens were examined within a few days; however, it was found that refrigeration at $4^{\circ} \mathrm{C}$. for as long as two months did not produce significant changes quantitatively, although some slight alteration in the migration rates were noted. It was found that there was no significant difference in the lipoprotein pattern between post-absorptive and fasting sera.

${ }^{1}$ Presented at the 5th International Congress of Clinical Pathology, Mexico City, 1963.

${ }^{2}$ Present address Guy's Hospital Medical School, London, S.E.1.

\section{METHOD}

The electrophoretic separation on cellulose acetate was performed in the usual manner (Kohn, 1958) using a veronal buffer $p \mathrm{H} 8 \cdot 6$, ionic strength 0.05 . The strips were $5 \times 10 \mathrm{~cm}$. We applied $10 \mu \mathrm{l}$. of serum to the strips. After running for two hours in the electrophoretic tank the strips were dried and cut along the middle. Half were stained with Ponceau $\mathbf{S}$ for proteins and the other half stained for lipoproteins, using Kohn's (1961) method based on Schiff's stain after preliminary ozonization. We performed this chemically with barium powder introduced in a beaker placed in an ozonizing chamber to which was added concentrated sulphuric acid. The strips were left in this atmosphere for 30 minutes rinsed in $N / 10,000$ $\mathrm{HCl}$ and placed in Schiff's stain for two hours. They were then washed three times in a reducing solution, for which potassium metabisulphite crystals in $N / 10$ $\mathrm{HCl}$ were used. The final wash was in $\mathrm{N} \mathrm{HCl}$. The strips were scanned on the Chromoscan instrument and results expressed as percentages. On several occasions the reproducibility of the technique and results were tested and affirmed.

\section{RESULTS}

The lipoproteins on cellulose acetate migrate at rates similar to the albumin and the $\alpha_{1}$ and $\alpha_{2}$ globulins. However, there are sometimes differences as can be seen in the strips photographed and reproduced here. The $\alpha_{1}$ lipoprotein has a smaller molecular weight than the $\alpha_{1}$ globulin and this permits it sometimes to migrate more quickly than the $\alpha_{1}$ globulin and indeed sometimes to overlap the albumin band slightly. It is seen, therefore, sometimes lying between, and overlapping, the $\alpha_{1}$ globulin on the one hand and the albumin on the other. The lipoproteins migrating in the albumin band occasionally form a sort of compressed ring with fast and slow components. We have called these lipoproteins the fast and slow albumins.

NORMAL CONTROLS Of the 27 cases we recognized three separate fractions in 16 cases, two fractions in nine cases, and four fractions in two cases. All these fractions would be readily scanned. In several strips 251 
FIG. 1. Three-fraction lipoprotein profile from a normal control.

FIG. 2. Three-fraction lipoprotein profile from a patient with multiple sclerosis.

FIG. 3. Three-fraction lipoprotein profile from a patient with multiple sclerosis showing a normal $\alpha_{2}$ lipoprotein in the presence of an increased $\alpha_{2}$ globulin.

FIG. 4. Four-fraction lipoprotein profile showing $a$ slow and fast albumin and a lipoprotein lying between the slow albumin and the $\alpha_{1}$ globulin.

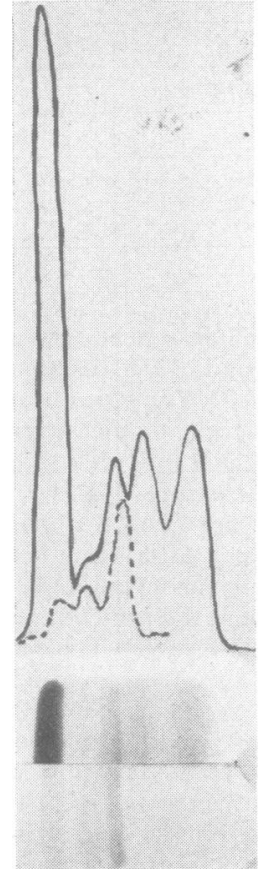

FIG. 1

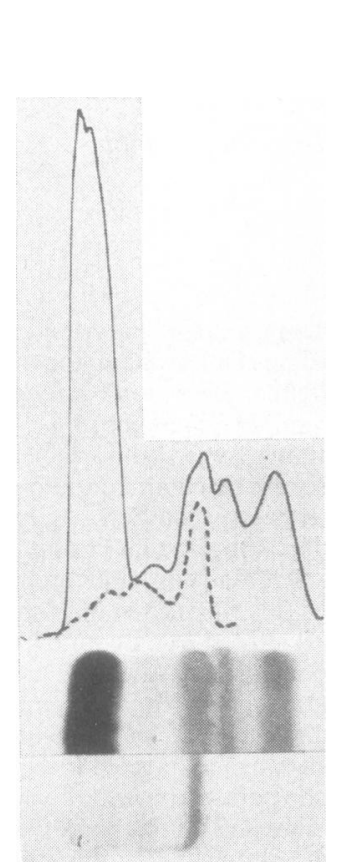

FIG. 2

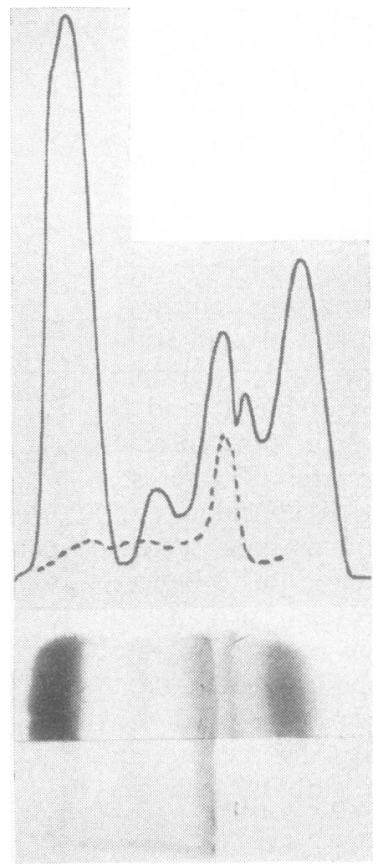

FIG. 3

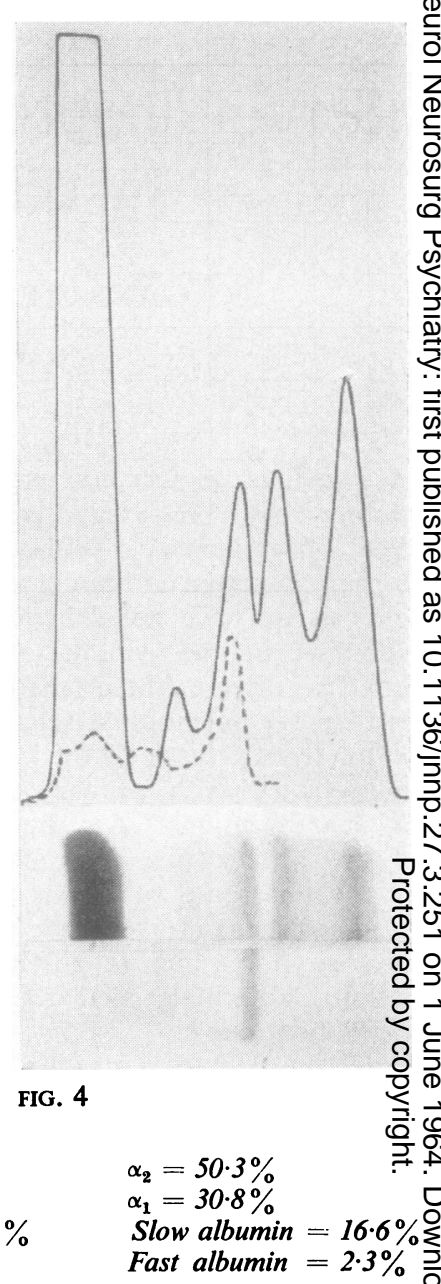

Fast albumin $=2 \cdot 3 \%$

Normal 1

$\alpha_{2}=56.5 \%$

$\alpha_{1}=30.0 \%$

Slow albumin $=13.5 \%$

$$
\begin{aligned}
& \alpha_{2}=53.4 \% \\
& \alpha_{1}=29.2 \% \\
& \text { Slow albumin }=17.4 \%
\end{aligned}
$$

there were traces of lipoprotein visible with the naked eye throughout the whole protein spectrum, but the amounts were so small that scanning was not possible.

The results (Table I) show clearly that most of the lipoproteins migrate in the $\alpha_{2}$ band and also that the $\alpha_{1}$ lipoproteins seem to have an inverse relationship with the slow albumins. Two band strips and three band strips are considered separately and for completeness the range of all the lipoprotein fractions we were able to scan are recorded in the third part of the table.

MULTIPLE SCLEROSIS We have considered the whole multiple sclerosis group together (Table II) and the active cases separately (Table III). Of the 28 active cases, 22 had three fractions and six had two fractions. Again the largest proportion of the lipoproteins migrate in the $\alpha_{2}$ band and there is an inverse

$$
\begin{aligned}
& \alpha_{2}=57.0 \% \\
& \alpha_{1}=27.1 \% \\
& \text { Slow albumin }=15.9 \%
\end{aligned}
$$

relationship between the $\alpha_{1}$ lipoproteins and the slow albumin. Fast albumin was not seen in the $\mathbb{D}$ active cases. Because of the small proportion of cases $\overrightarrow{\vec{P}}$ of multiple sclerosis with a fast albumin, and because $\frac{3}{3}$ of its presence in the normal group, no particular significance was attached to its absence from the 28 . cases of active disease.

Of the whole multiple sclerosis group there were three fractions in 32 cases, two fractions in seven? cases, and four fractions in four cases.

The tables show the proportion of the various lipoproteins present in two-fraction and three-fraction strips, and again, as with the normal group, the third part of Tables II and III shows the overall range for each lipoprotein fraction in the group $\frac{D}{0}$ considered as a whole.

Statistical comparison of the $\alpha_{1}, \alpha_{2}$, and slow N albumin lipoprotein fractions between the whole multiple sclerosis group, the active multiple sclerosis 
TABLE I

LIPOPROTEINS IN NORMAL GROUP

\begin{tabular}{|c|c|c|c|}
\hline$\alpha_{2}$ Lipoprotein $(\%)$ & $\begin{array}{l}\alpha_{1} \text { Lipo- } \\
\text { protein }(\%)\end{array}$ & $\begin{array}{l}\text { 'Slow' } \\
\text { Albumin (\%) }\end{array}$ & $\begin{array}{l}\text { 'Fast' } \\
\text { Albumin }(\%\end{array}$ \\
\hline $\begin{array}{l}\text { Three-fraction strips }( \\
\text { Range } 49 \cdot 2-61 \cdot 1 \\
\text { Mean } \quad 55 \cdot 6 \\
\text { S.D. } 4 \cdot 1 \\
\text { Two-fraction strips }(9\end{array}$ & $\begin{array}{l}\text { cases) } \\
15 \cdot 6-32 \cdot 1 \\
26 \cdot 0 \\
4 \cdot 9 \\
\text { ses) }\end{array}$ & $\begin{array}{l}10 \cdot 3-26 \cdot 0 \\
17 \cdot 4 \\
4 \cdot 3\end{array}$ & \\
\hline $\begin{array}{l}\alpha_{2} \\
\text { Range } \quad 51 \cdot 3-67.4 \\
\text { Mean } \quad 58.5 \\
\text { S.D. } \quad 5.2 \\
\text { Two-, three-, and four }\end{array}$ & $\begin{array}{l}\alpha_{1} \\
32 \cdot 6-48 \cdot 7 \\
41 \cdot 5 \\
5 \cdot 2 \\
\text { action strips }(\end{array}$ & cases) & \\
\hline $\begin{array}{lr}\alpha_{2} & \\
\text { Range } & 49.2-67.4 \\
\text { Mean } & 56.5 \\
\text { S.D. } & 4.6\end{array}$ & $\begin{array}{l}\alpha_{1} \\
15.6-48.7 \\
31.2 \\
8.9\end{array}$ & $\begin{array}{l}10 \cdot 3-26 \cdot 0 \\
17 \cdot 4 \\
4 \cdot 3\end{array}$ & $\begin{array}{l}3 \cdot 1-9 \cdot 6 \\
6 \cdot 4\end{array}$ \\
\hline
\end{tabular}

TABLE II

LIPOPROTEINS IN ALL CASES OF MULTIPLE SCLEROSIS $\begin{array}{llll}\alpha_{2} \text { Lipoprotein (\%) } & \begin{array}{l}\alpha_{1} \text { Lipo- } \\ \text { protein (\%) }\end{array} & \begin{array}{l}\text { 'Slow' } \\ \text { Albumin (\%) }\end{array} & \text { 'Fast' } \\ & \text { Albumin (\%) }\end{array}$

Three-fractions (32 cases)

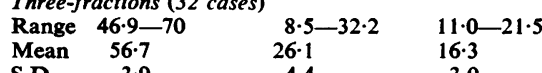

$\begin{array}{llll}\text { S.D. } & 3.9 & 4.4 & 3.0\end{array}$

Two fractions ( 7 cases)

Range $56 \cdot 0-79 \cdot 5 \quad 20 \cdot 5-44 \cdot 0$

Mean $\quad 64.6 \quad 35.4$

$\begin{array}{lrr}\text { S.D. } & 8 \cdot 3 & 8 \cdot 3\end{array}$

Whole group ( 43 cases)

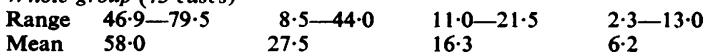

M.D. $\quad 6 \cdot 3$

$6 \cdot 2$

3.0

TABLE III

LIPOPROTEINS IN CLINICALLY ACTIVE CASES OF MULTIPLE SCLEROSIS

$\alpha_{2}$ Lipoprotein (\%) $\alpha_{1}$ Lipoprotein (\%) 'Slow' Albumin (\%)

\begin{tabular}{|c|c|c|c|}
\hline \multicolumn{4}{|c|}{ Three fractions ( 22 cases) } \\
\hline Range & $46 \cdot 9-70$ & $8 \cdot 5-32 \cdot 2$ & $11 \cdot 0-21 \cdot 5$ \\
\hline Mean & $57 \cdot 8$ & $25 \cdot 4$ & $16 \cdot 1$ \\
\hline S.D. & $4 \cdot 6$ & $5 \cdot 3$ & $5 \cdot 7$ \\
\hline \multicolumn{4}{|c|}{ Two fractions (6 cases) } \\
\hline Range & $56 \cdot 0-79 \cdot 5$ & $\begin{array}{l}20 \cdot 5-44 \\
35 \cdot 4\end{array}$ & \\
\hline $\begin{array}{l}\text { Mean } \\
\text { S.D. }\end{array}$ & $\begin{array}{r}64 \cdot 6 \\
8 \cdot 3\end{array}$ & $\begin{array}{r}35 \cdot 4 \\
8 \cdot 3\end{array}$ & \\
\hline
\end{tabular}

group, and the normal group using Student's $t$ test is shown in Table IV. There is no significant increase in any of the fractions, although there appears to be a significant decrease in the $\alpha_{1}$ lipoproteins in the multiple sclerosis group considered as a whole. This is not evident if the active cases only are considered.

We (Gavrilescu et al., 1961; Gavrilescu and McMenemey, 1964) and others (Durrum, Paul and Smith, 1952; Swahn, 1952) have previously reported an increase in the $\alpha_{2}$ globulin in the serum in multiple sclerosis. This finding was confirmed in the present series and $\alpha_{2}$ globulin increase above the upper limit of normal $(0.9 \mathrm{~g} . \%)$ was noted in $57 \%$ of the cases.
TABLE IV

COMPARISON OF MULTIPLE SCLEROSIS GROUP WITH NORMALS

Lipoproteins

Three fractions

$\alpha_{2}$ (MS) compared with $\alpha_{2}$ (N)

$\alpha_{1}$ (MS) compared with $\alpha_{1}$ (N)

'Slow' albumin (MS) compared with

slow albumin (N)

$P<0.4>0.3$
$P<0.5>0.4$

Two fractions

$\alpha_{2}$ (MS) compared with $\alpha_{2}$

$\alpha_{1}$ (MS) compared with $\alpha_{1}$

Total group

$\alpha_{2}$ (MS) compared with $\alpha_{2}$ (N)

$\alpha_{1}$ (MS) compared with $\alpha_{1}$ (N)

'Slow' albumin (MS) compared with

slow albumin (N)

$P<0.4>0.3$

$P<0.2>0.1$

$\mathbf{P}<0.2>0.1$

$\mathbf{P}<0.3>0.2$

$\mathbf{P}<0.05>0.02$

$P<0.05$ is considered significant

$P<0.4>0.3$

TABLE V

COMPARISON OF ACTIVE MULTIPLE SCLEROSIS CASES WITH NORMALS

Lipoproteins

$$
\begin{aligned}
& P<0.4>0.3 \\
& P<0.5>0.4 \\
& P<0.4>0.3 \\
& P<0.2>0.1 \\
& P<0.2>0.1 \\
& P<0.1>0.05 \\
& P<0.7>0.6 \\
& P<0.3>0.2
\end{aligned}
$$

$\alpha_{1}$ (MS) compared with $\alpha_{1}(\mathrm{~N})$

'Slow' albumin (MS) compared with

'slow' albumin (N)

\section{DISCUSSION}

Macheboeuf in 1929 was the first to mention lipoproteins, which he considered as 'cenapses' of linked cholesterol, lecithin, or fatty substance to the protein molecule.

Much later in 1953 with the work of Durrum et al. (1952), based on paper electrophoresis, wider possibilities were opened for their study. The initial staining techniques, promoted by Kunkel and Slater (1952) Rosenberg (1952), Swahn (1952), and others, experimenting with Sudan black B, Sudan IV, Sudan III, and oil red $O$, were not very satisfactory on paper strips. Because of this we decided three years ago to abandon the use of paper and began the study afresh using cellulose acetate following Kohn's method.

Multiple sclerosis is not known to have a somatic component outside the central nervous system. For this reason the finding of an elevated $\alpha_{2}$ globulin in $57 \%$ of cases after due care was taken to exclude those with complicating inflammatory conditions such as urinary infection, is of interest. The work above has shown that the elevation in the $\alpha_{2}$ globulins is 
not due to, or related to, an increase in the $\alpha_{2}$ lipoproteins.

Zilkha and McArdle (1963), using a chromatographic technique, have produced strong evidence that breakdown products of myelin are detectable in phospholipid increases in cerebrospinal fluid. Roboz, Hess, Forster, and Temple in 1954 postulated that if the breakdown products of myelin found their way into the serum they would be expected to act as neutral fat. They investigated the serum lipoproteins in multiple sclerosis, using paper electrophoresis but were unable to detect any increase in the neutral fat. Even if their postulate were correct, because of the great dilution factor involved one would not expect to find any changes by electrophoretic methods. We, too, using a more sensitive technique, have been unable to detect any increase in the lipoproteins in the serum.

\section{SUMMARY}

The serum lipoproteins, using cellulose acetate electrophoresis, were investigated in 27 normal controls and in 43 cases of multiple sclerosis. There was no significant increase in the lipoproteins.

There was a slight but significant decrease in the $\alpha_{1}$ lipoproteins in the multiple sclerosis group if the active and chronic cases were considered together. There was no such decrease apparent in the active group alone.

The increase in the $\alpha_{2}$ serum globulins reported in previous papers was confirmed in the present studyc and was found in $57 \%$ of cases. This increase doeso not appear to be related to an increase in the lipo- 0 proteins.

We express our thanks to Mr. G. Cox for the photography and to Miss A. M. Garbis for help with the calculations. One of us (K.G.) is in receipt of a fellowship from the Multiple Sclerosis Society of the United Kingdom.

\section{REFERENCES}

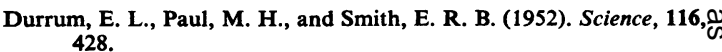

Gavrilescu, K., Jellinek, E. H., and McMenemey, W. H. (1961). $\vec{\circ}$ Wld Neurol., 2, 709.

- , and McMenemey, W. H. (1964). Suppl., Z. Immun. Forsch., in the press.

Kohn, J. (1958). Nature (Lond.), 181, 839.

(1961). Ibid., 189, 312.

Kunkel, H. G., and Slater, R. J. (1952). J. clin. Invest., 31, 677.

Macheboeuf, M. A. (1929). Bull. Soc. Chim. biol. 11, 268 and 485.

Roboz, E., Hess, W. C., Forster, F. M., and Temple, D. M. (1954). Nu A.M.A. Arch. Neurol. Psychiat., $72,154$.

Rosenberg, I. N. (1952). Proc. Soc. exp. Biol. (N.Y.), 80, 751.

Swahn, B. (1952). Scand. J. Clin. lab. Invest., 4, 98.

Zilkha, K. J., and McArdle, B. (1963). Quart.J. Med., 32, 79. 